\title{
Xylose and Arabinose Fermentation to Produce Ethanol by Isolated Yeasts from Durian (Durio zibethinus L.) Fruit
}

\author{
Hermansyah $^{1 *}$, Fachrijal ${ }^{1}$, Miksusanti $^{1}$, Fatma $^{1}$, Getari Kasmiarti ${ }^{2}$, Almunadi T. Panagan' \\ 'Chemistry Department, Faculty of Mathematics and Natural Sciences, Sriwijaya University, \\ Palembang, Indonesia \\ ${ }^{2}$ Environmental Management Study Program, Graduate School Sriwijaya University, \\ Palembang, Indonesia
}

*Corresponding author email: hermansyah@unsri.ac.id

Received August 5, 2019; Accepted October 10, 2019; Available online November 30, 2019

\begin{abstract}
Xylose and arabinose are pentose sugars that present in hemicellulose, part of lignocellulose biomass. These pentose sugars can be fermented by yeast into ethanol. The aim of this research was to utilize yeast isolated from durian fruit (Durio zibethinus L.) in fermentation of xylose and arabinose to produce bioethanol. Phenotypic test of isolates was conducted by growing the isolates in various agar media, i.e. YPD (Yeast Peptone Dextrose), YPA (Yeast Peptone Arabinose), and YPX (Yeast Peptone Xylose) containing dextrose, arabinose, xylose, respectively, as sole carbon source to see cell growth. The yeast isolates were further identified using API AOC 20C kit method. Yeast isolates were applied for fermentation of glucose, arabinose, and xylose in incubated cultures. Ethanol production in the fermentation was analyzed by gas chromatography. Yeast isolates were identified as Kodamaea ohmeri, Candida famata, Candida guilliermondii, and Crytococcuc laurentii. Based on gas chromatography data, it was found that ethanol produced in the fermentation for three days, the highest ethanol content on xylose substrate was fermented by Candida famata- $A$ which is $0.021 \%$ ( $/ \mathrm{v}$ ) ethanol resulted from initial concentration of $5 \%$ xylose $(\mathrm{w} / \mathrm{v})$. While on arabinose substrate, the highest ethanol content was fermented by Crytococcus laurentii- $B$ which is $0.0034 \%(\mathrm{v} / \mathrm{v})$ ethanol resulted from initial concentration of $5 \%$ arabinose $(w / v)$.
\end{abstract}

Keywords: Yeast, bioethanol, xylose, arabinose, Durio zibethinus L.

\section{INTRODUCTION}

In the second generation of biofuel production, biomass has been attracting an attention for renewable energy development. Bioethanol produced as the alternative liquid fuel by fermentation using variety of substrates such as monosaccharides (hexoses and pentoses) and polysaccharides (starch). $\mathrm{D}$-xylose and L-arabinose are pentose derived from hemicelluloses that have great potential as fermentation substrate (Yang, et al., 2015). To reduce competition using of edible sources or food as raw material is reason for us to utilize lignocellulosic biomass as raw material of biofuel especially for production of ethanol biofuel. Lignocellulosic biomass is abundant including empty fruit bunch of oil palm tree, sugarcane bagasse, rice straw, switchgrass, etc and it is considered as an attractive feedstock (Cardona, Quintero, and Pas, 2010; Chen, Wu, and Fukuda, 2008).

By converting lignocellulosic biomass from agricultural or household waste into bioethanol, it can overcome not only energy crisis problem, but also solves environmental problem. Lignocellulose is a complex biopolymer mainly composed of three components: $\quad 35-50 \%$ cellulose, $20-32 \%$ hemicellulose, and 10-35\% lignin (Sun and Sun, 2015). Glucose is the most abundant component in both cellulose and hemicellulose and can be fermented readily to produce ethanol. Pentose sugars in hemicellulose such as L-arabinose and D-xylose also could be converted into bioethanol (Olofsson, Bertisson, and Lidden, 2008). Thus, fermentation of all sugars content in the feedstock, hexose and pentose sugar should be considered in utilization of lignocellulose biomass (Bettiga, Bengtsson, HahnHagerdal, \& Gorwa-Grauslund, 2009).

One of the consideration for the successful fermentation dertermined by organism's ability to naturally ferment pentose sugars (arabinose and xylose) (Nidetzky, Novy, Krahulec, Longus, Klimacek, 2013). Hexose and pentose sugar which can be liberated by hydrolysis and fermented to ethanol. Generally, L-arabinose is part of pentose. It can be converted at high yields and rates together with the most abundant sugars, such as glucose and xylose (Maris, et al., 2010). Both xylose and arabinose need to be efficiently converted to consider the economic cost. They could be produced by some methods: 
enzymatic hydrolysis, chemical synthesis, microbial fermentation, and acid hydrolysis (Zhu, Yu, Liu, Zhang, and Zhang, 2017).

Saccharomyces cerevisiae has been utilized for producing ethanol in the beverage industry, and furthermore it has been utilizedfor producing bioethanol in recent decades (Hahn-Hagerdal, Galbe, Gorwa-Grauslund, Liden, and Zacchi, 2006). Wild type strain S. cerevisiae can't ferment either arabinose or xylose as carbon source to bioethanol. There are two ways to obtain microbial agent which can convert arabinose and xylose into bioethanol. Firstly, by developing a recombinant $S$. cerevisiae strain which can over-express of genes encoding enzymes in the pentose-phosphate pathway (Bettiga, et al., 2009) and secondly, screening for alternative microbes which could ferment xylose and arabinose as carbon source. In this study, we isolated some microbes from durian fruit (Durio zibethinus L.) which applied in fermentation either of arabinose or xylose as sole carbon source to produce ethanol as the inovation in developing bioethanol production. As we know that yeast cells are both saprophyte and parasite in fruit which contains simple sugars. Collonization of yeast is often indicated by synthesis of alcohol and will lead to the rotting of fruits (Ruriani, Sunarti, and Meryandini, 2012).

\section{EXPERIMENTAL SECTION}

\section{Yeast strains and culture conditions}

Yeast Kodamaea ohmeri, Candida famata, Candida guilliermondii, and Crytococcuc laurentii were isolated from durian fruit and indentified by API 20C AUX Kit yeast identification system (BioMerieux). These yeasts were growing in the agar media which are YPD medium contains $10 \mathrm{~g} / \mathrm{L}$ yeast extract, $20 \mathrm{~g} / \mathrm{L}$ peptone, $20 \mathrm{~g} / \mathrm{L}$ glucose; YPX medium contains $10 \mathrm{~g} / \mathrm{L}$ yeast extract, $20 \mathrm{~g} / \mathrm{L}$ peptone, $20 \mathrm{~g} / \mathrm{L}$ xylose; YPA agar medium contains $10 \mathrm{~g} / \mathrm{L}$ yeast extract, $20 \mathrm{~g} / \mathrm{L}$ peptone, $20 \mathrm{~g} / \mathrm{L}$ arabinose), agar media were prepared by adding and $20 \mathrm{~g} / \mathrm{l}$ bacto agarinto either YPD, YPX, or YPA media. These agar media contain $\mathrm{MgSO}_{4} .7 \mathrm{H}_{2} \mathrm{O}$, $\mathrm{NaH}_{2} \mathrm{PO}_{4},\left(\mathrm{NH}_{4}\right)_{2} \mathrm{HPO}_{4}$, ethanol, $\mathrm{NaOH}, \mathrm{NaK}$ tartrate.

\section{Isolation of yeast from durian fruit (Durio zibethinus L.)}

Four-yeast strains have been isolated from durian fruit (Durio zibethinus L.) which obtained from local market. Durian fruit in sterile water solution was prepared in various dilution $10^{-5}$ to $10^{-1}$ by dissolved 10 gram of durian. The solution was spread on YPD agar medium containing $100 \mu \mathrm{g}$ tetracycline to inhibit bacterial growth, and incubated at $30{ }^{\circ} \mathrm{C}$ for 2 days. Single colonies were picked, purified, and further identified.

\section{Yeast Identification}

Yeast isolates were identified using yeast identification system API 20C AUX Kit (BioMerieux) following company's procedure with small modification (Hermansyah, Adhiyanti, Julinar, Rahadiyanto, and Susilawati, 2017).

\section{Phenotypic assay}

Phenotypic assay was carried out according to previous procedure (Hermansyah, Novia, Sugiyama, and Harashima, 2015). Cell were grown on YPD, YPX, and YPA agar media and incubated at $30{ }^{\circ} \mathrm{C}$ for $2-4$ day. Cell growth was observed whether sensitive or resistant to the media.

\section{Fermentation test and analysis of ethanol content}

The fermentation method used in this study according to described paper (Benjaphokee, et al., 2012) with some modification, especially to determine ethanol content using gas chromatography. Cell inoculum which grown in two days on YPD medium was transferred into YPD, YPA, and YPX media with nutrient. Nutrient for ethanol fermentation and analysis consisted of $1 \mathrm{~g} / \mathrm{l}$ yeast extract, $0.5 \mathrm{~g} / \mathrm{L}$ $(\mathrm{NH} 4)_{2} \mathrm{HPO}_{4}, 0.025 \mathrm{~g} / \mathrm{l} \mathrm{MgSO}_{4} .7 \mathrm{H}_{2} \mathrm{O}$, and $0.1 \mathrm{M}$ $\mathrm{NaH}_{2} \mathrm{PO}_{4}$. Cultures were incubated with shaking at room temperature for 3 days to allow the ethanol establishment. Ethanol produced during fermentation were analyzed using gas chromatography (GC 2010 Shimadzu) under the following condition: column length and diameter $30 \mathrm{~m}, 0.25 \mathrm{~mm} ; \mathrm{N}_{2}$ carrier gas flow rate $136.3 \mathrm{~mL} / \mathrm{min}$, pressure $100 \mathrm{kPa}$; flame ionization detector, temperature of injector, column, and detector were $150{ }^{\circ} \mathrm{C}, 60-240{ }^{\circ} \mathrm{C}$, and $200^{\circ} \mathrm{C}$, respectively. Ethanol procudtion data were identified by comparing the initial arabinose and xylose substrate concentrarion with the ethanol yield that fermented by isolated yeast.

\section{RESULTS AND DISCUSSION}

Yeast isolates have been successfully isolated from durian fruit, and then identified using API 20C AUX kit (Biomerieux). This kit based on assimilation assay where yeast isolates were grown on 19 sugars i.e. Dglucose, glycerol, calcium 2-keto gluconate, Larabinose, D-xilose, adonitol, xylitol, D-galactose, inositol, D-sorbitol, metil- $\alpha$-D-glucopyranoside, Nacetil-glucosamin, D-celliobiose, D-lactose, Dmaltose, D-sucrose, D-trehalose, D-melezitose, Drafinose) comparing with control.

Based on the comparing result between observational and software database indentification data from API 20C AUXkit (Biomerieux) as shown in Figure 1 and Table 1, six isolates (colony no 13, 14, $15,16,17$, and 18) were identified as K.ohmeri, C. famata (two isolates designed as $C$. famata-A and $C$. famata-B), C. guilliermondii, and C. laurentii (two isolates designed as $C$. laurentii-A and $C$. laurentii-B). This result indicated that durian fruit contains various of yeast which may have a potent in some applications. It has also isolated and selected of suitable yeast strain for bioethanol fermentation in Brazil, and suggested the great biodiversity found in distillery environments could be an important source 


\section{Kodamaea ohmeri}
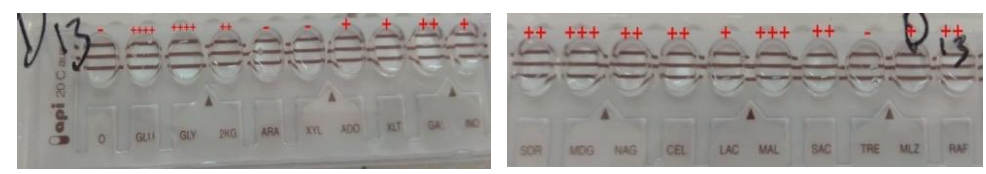

2. Candida famata
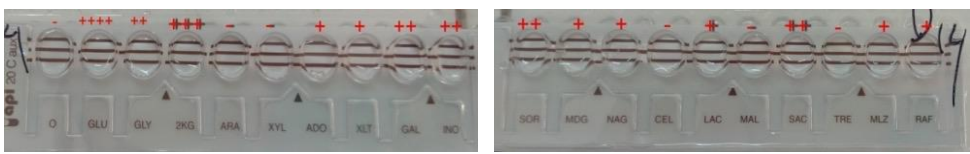

3. Candida guilliermondii
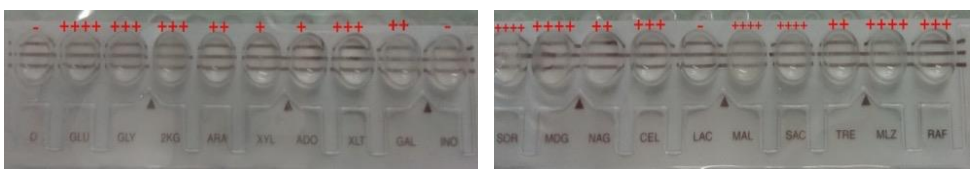

4. Crytococcus laurentii
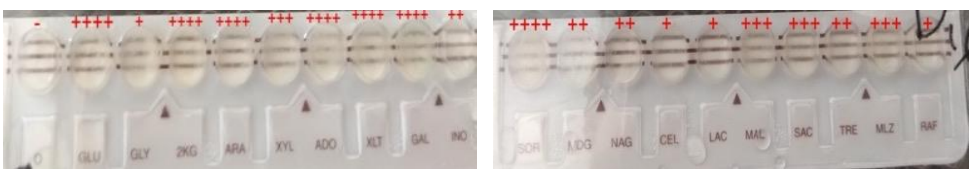

5. Crytococcus laurentii
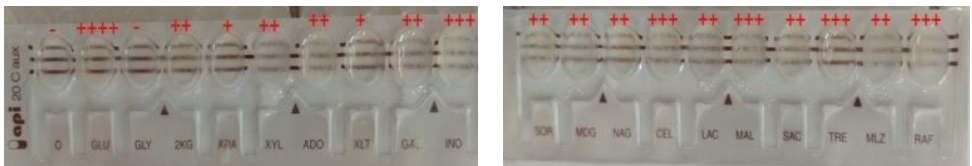

6. Candida famata
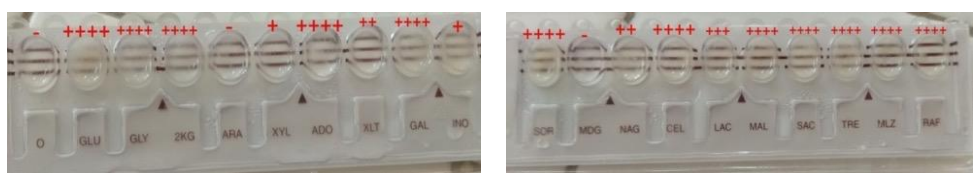

Figure 1. Identification 6 isolates using API 20C AUX kit (Biomerieux); 0 = negative control; Glu = D-glucose; Gly = glycerol; $2 \mathrm{~kg}=$ calcium 2-keto gluconate; Mlz = D-melezitose; Mal = D-maltose; Sac = D-sucrose; Tre = D-trehalose; Nag = N-acetil-glucosamin; Cel = D = celliobiose; Raf = Rafinose; Ado = Adonitol; Xlt = xylitol; Gal = D-galactose; Lac = D-lacotose; Sor = D-sorbitol; Ino = inositol; Xyl = D-xylose; Ara $=\mathrm{L}$ arabinose.

Table 1. Turbidity scale of isolates growth assay using API 20C AUX Kit

\begin{tabular}{|c|c|c|c|c|c|c|}
\hline Sugar & D13 & D14 & D15 & D16 & D17 & D18 \\
\hline 0 (blank) & - & - & - & - & - & - \\
\hline GLU & ++++ & ++++ & ++++ & ++++ & ++++ & ++++ \\
\hline GLY & ++++ & ++ & +++ & + & - & ++++ \\
\hline $2 K G$ & ++ & +++ & +++ & ++++ & ++ & ++++ \\
\hline ARA & - & - & ++ & ++++ & + & - \\
\hline$X Y L$ & - & - & + & +++ & ++ & + \\
\hline ADO & + & + & + & ++++ & ++ & ++++ \\
\hline XLT & + & + & +++ & ++++ & + & ++ \\
\hline GAL & ++ & ++ & ++ & ++++ & ++ & ++++ \\
\hline INO & + & ++ & - & ++ & +++ & + \\
\hline SOR & ++ & ++ & ++++ & ++++ & ++ & ++++ \\
\hline MDG & +++ & + & ++++ & ++ & ++ & - \\
\hline NAG & ++ & + & ++ & ++ & ++ & ++ \\
\hline CEL & ++ & - & +++ & + & +++ & ++++ \\
\hline LAC & + & + & - & + & ++ & +++ \\
\hline MAL & +++ & - & ++++ & +++ & +++ & ++++ \\
\hline SAC & ++ & ++ & ++++ & +++ & ++ & ++++ \\
\hline TRE & - & - & ++ & ++ & +++ & ++++ \\
\hline MLZ & + & + & ++++ & +++ & ++ & ++++ \\
\hline RAF & ++ & + & +++ & + & +++ & ++++ \\
\hline
\end{tabular}




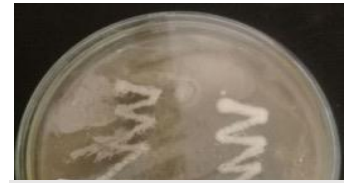

D13

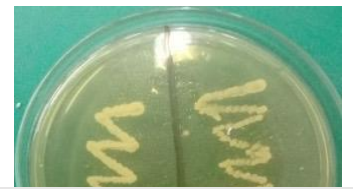

D15 D16

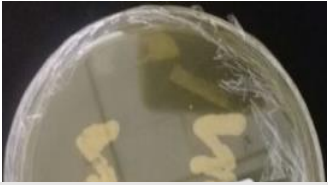

D17 D18

a) Isolates D13, D14, D15, D16, D17, and D18 on YPD media

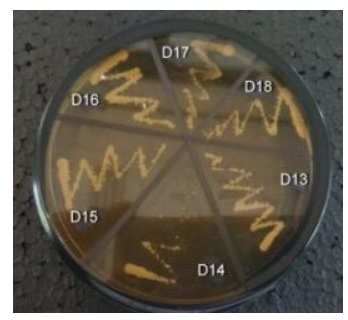

b) Isolates D13, D14, D15, D16, D17, and D18 on YPA medium

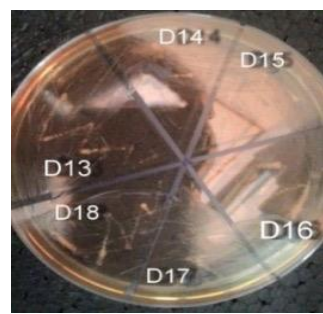

c) Isolates D13, D14, D15, D16, D17, and D18 on YPX medium

Figure 2. Phenotypic test of yeast isolates D13, D14, D15, D16, D17, and D18 on YPD, YPA, and YPX media containing glucose (a), arabinose (b), and xylose (c) respectively as carbon source.

of strain (Basso, de Amorim, Oliveira, and Lopes, 2008).. However, they can't grow on all media test.

Although cultures were cultivated for 5 days. They can only grow on media which contains specific sugar for growth. The ambient temperature favoured microbial growth incuabted at $25^{\circ} \mathrm{C}$ for 5 days (Voon, Hamid, Rusul, Osman, and Queck, 2006). Fatoni and Zusfahair (2012) reported that tapioca waste hydrolized thermophilic amylase was fermented at temperature of $37^{\circ} \mathrm{C}$ for 24 hours resulting $0.29 \%$ $(\mathrm{v} / \mathrm{v})$ ethanol. Phenotypic test was carried out to see characteristics of structural, biochemical, and physiological of isolates and this characteristic related to genotype and environment or their interaction. The results showed that yeast isolates grow faster and larger on YPD medium than on YPA or YPX media (Figure 2). This data indicated that yeast isolates utilized and assimilated glucose as carbon source better than arabinose or xylose.

\section{Fermentation using microbial agent yeast isolates}

To see whether yeast isolates can convert pentose sugars into ethanol, then these yeast isolates were applied as microbial agent to ferment arabinose and xylose as a sole carbon source in YPA, and YPX media. Fermentation of xylose and arabinose by microbial agent isolates K. ohmeri (D13), C. famata (D14 or C. famata-A and D18 or C. famata-A), C. guilliermondii (D15), and C. laurentii (D16 or C. laurentii-A and D17 or C. laurentii-B) was observed their ethanol product after 3 days incubating at room temperature with shaking. Shaking treatement does not allow a limited degree of headspace exchange and limit the evaporation, it will make the fermentation process more effective.
Based on gas chromatography data, it was found that the highest ethanol content was $0.021 \%(\mathrm{v} / \mathrm{v})$ produced from $5 \%(\mathrm{w} / \mathrm{vv})$ xylose substrate using $C$. famata-A (isolate D14) (Figure 3). As the goal of the fermentation is to find microorganism that effectively produce bioethanol from the second abundant sugar, xylose and arabinose. Furthermore, C. Famata work well at temperatures around $25{ }^{\circ} \mathrm{C}-30{ }^{\circ} \mathrm{C}$ and it natural habitat normally impose a continuous osmotic stress, due to low water activity in intracelluler accumulation of polyhiydroxy alcohol in order to fermented xylose. C. famata acknowledge as unicelluler yeast, it is easier to distribute in a largescale fermentor which is good reason for bioethanol production with higher yields (Sibirni, Fedorovych, Sybirna, Yatsyshyn, and Dmytruk, 2011).C. famata in lagume-based fermented food and C. Famata preferentially colonize fruit surface in Japan (Hommel and Ahnert 1999).

While on the arabinose substrate, the highest ethanol content was $0.0034 \%(\mathrm{v} / \mathrm{v})$ produced from $5 \%$ arabinone substrate using $C$. laurentii-B (isolate D17) (Figure 4). Generally plants contain abundant $C$. laurentii compared to other microorganism because it produce mycocins in soil. It is also one of fast growing yeast and appear after 24 hours of incubation at 30 ${ }^{\circ} \mathrm{C}$ (Grange, Rensburg, Ncube, and Malhuvele, 2017). In the various fruit, Crytococcus laurentii known as antagonistic yeast that can remarkably induce resistance in pears, jujube fruits, peaches, table grapes, and cherry tomato and lessen postharvest fungal diseases in pear, apple, and strawberry (Tang, et al., 2019). Thus ability from C. laurentii might be bocome the reason why it presents in durian.

In this study, ethanol produced this fermentation was low concentration; we did not optimize the 
condition. There are many factors that affected the condition such as $\mathrm{pH}$, fermentation temperature, dissolved oxygen, and many others. Therefore, future experiment optimization should be conducted to obtain higher concentration. Xylose and arabinose has been fermented by recombinant $S$. cerevisiae with higher concentration of ethanol. The recombinant was constructed by inserting enzymes which involved in pentose utilization pathway. By the anaerob condition, the recombinant strain fermented simultaneous co-utilization of xylose and arabinose significantly reduced formation of the by-product xylitol, which contributed to improved ethanol production (Bettiga, et al., 2009). S. cerevisiae is important biocatalysis because its cost-effectiveness compared to the other fermenting agents that are produce zero chemical waste. Moreover, the production of bioethanol by $S$. cerevisiae has been taking key role in industry as an ideal biocatalysis for bioethanol production in sugar-containing nutrient medium (Monir, Aziz, Yousuf, and Alam, 2019).

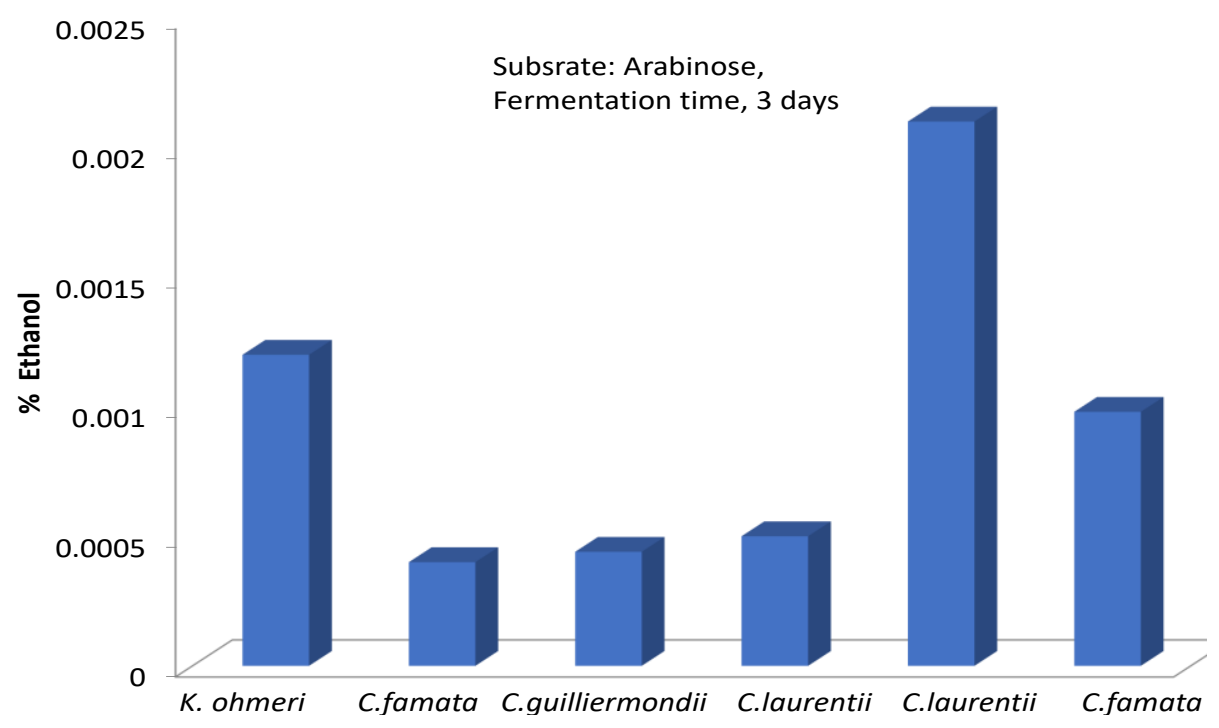

Figure 3. Fermentation of arabinose as sole carbon source using $K$.ohmeri, $C$. famata (two isolates designed as C. famata-A and C. famata-B), C. guilliermondii, and $C$. laurentii (two isolates designed as $C$. laurentii-A and $C$. laurentii-B) for three days.

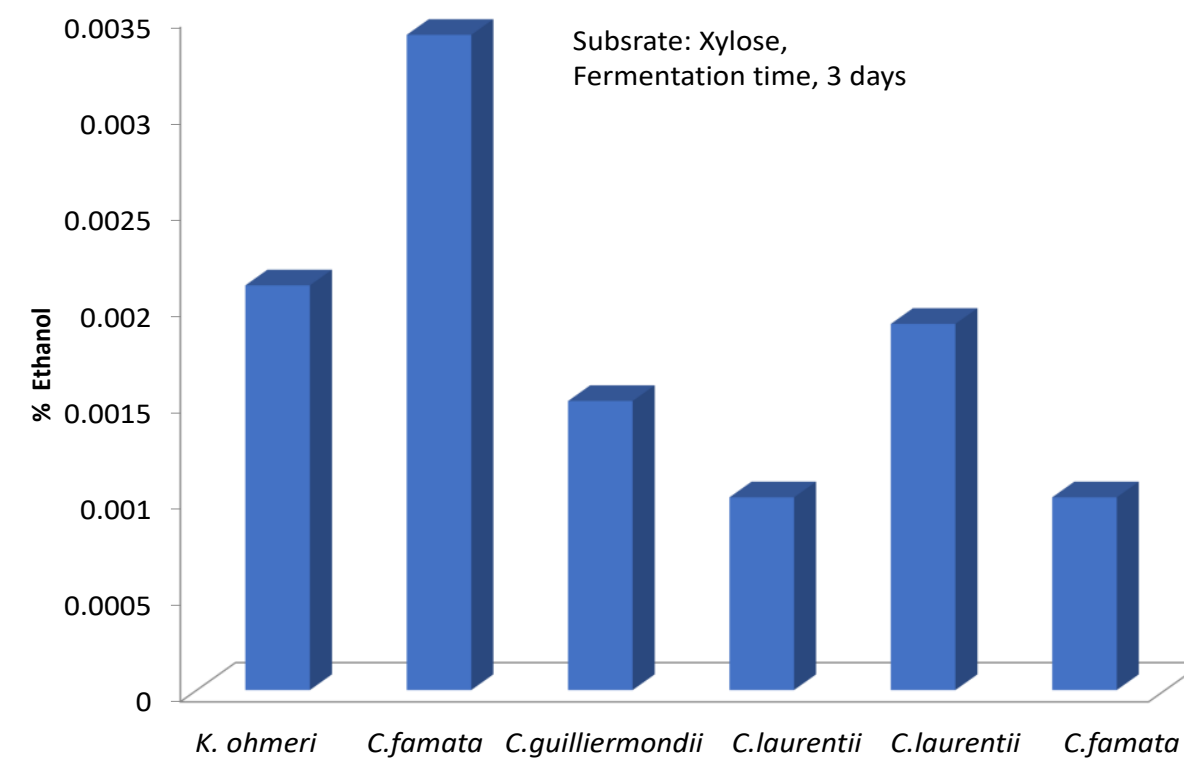

Figure 4. Fermentation of xylose as sole carbon source using $K$. ohmeri, $C$. famata-A, C. famata-B, C. guilliermondii, and C. laurentii-A and C. laurenti$B$ for three days. 


\section{CONCLUSSIONS}

Six yeast isolates were identified from durian fruit, i.e.Kodamaea ohmeri, Candida famata-A, Candida famata- $B$, Candida guilliermondii, Crytococcuc laurentii- $A$, and Crytococcuc laurentii- $B$. Fermentation test showed that the highest ethanol content on $5 \%$ $(\mathrm{w} / \mathrm{v})$ xylose substrate achieved by Candida famata-A $0.021 \%(\mathrm{v} / \mathrm{v})$ while $5 \%(\mathrm{w} / \mathrm{v})$ of arabinose substrate fermented by Crytococcus laurentii-B $0.0034 \%(\mathrm{v} / \mathrm{v})$.

\section{ACKNOWLEDGEMENTS}

This work was supported by Hibah Kompetitif DIPA Sriwijaya Universitas Research grant 2018.

\section{REFERENCES}

Basso, L.C., de Amorim, H.V., Oliveira, A.J., \& Lopes, M.L. (2008). Yeast selection for fuel ethanol production in Brazil. FEMS Yeast Research. 8(7): 1155-1163.

Benjaphokee, S., Hasegawa, D., Yokota, D., Asvarak, T., Auesukaree, C., Sugiyama, M., Kaneko, Y., Boonchird, C., \& Harashima, S. (2012). Highly efficient bioethanol production by a Saccharomyces cerevisiae strain with multiple stress tolerance to high temperature, acid and ethanol. New Biotechnology. 29(3): 379-386.

Bettiga, M., Bengtsson, O., Hahn-Hagerdal, B., \& Gorwa-Grauslund, M.F. (2009). Arabinose and xylose fermentation by recombinant Saccharomyces cerevisiae expressing a fungal pentose utilization pathway. Microbial Cell Factories. 8(40).

Cardona, C.A., Quintero, J.A., \& Paz, I.C. (2010). Production of bioethanol from sugarcane bagasse: Status and perspectives. Bioresource Technology. 101(13): 4754-4766.

Chen, J.P., Wu, K.W., \&Fukuda, H. (2008). Bioethanol production from uncooked raw starch by immobilized surface-engineered yeast cells. Applied Biochemistry Biotechnology. 145(1-3): 59-67.

Fatoni, A. \& Zusfahair. (2012). Thermophilic amylase from Thermus sp. isolation and its potential application for bioethanol production. Songklanarin Journal of Science and Technology. 34(5): 525-531.

Grange, C. D., Rensburg, E. L. J., Ncube, I., Malhuvele, R. 2017. Isolation of fungi from dung of wild herbivores for application in bioethanol production. Brazilian Journal of Microbiology. 48 (1): 648-655.

Hahn-Hagerdal, B., Galbe, M., Gorwa-Grauslund, M.F., Liden, G.,\& Zacchi, G. 2006. Bioethanol, the fuel of tomorrow from the residues of today. Trends Biotechnology. 24(12): 549-56.

Hermansyah, Adhiyanti, N., Julinar, Rahadiyanto, K.Y., \& Susilawati. (2017). Identification of candida species by assimilation and multiplex-
PCR methods. Journal of Chemical Technology and Metallurgy. 52(6): 1070-1078.

Hermansyah, Novia, Sugiyama, M., \&Harashima, S. (2015). Candida tropicalis isolated from tuak, a north Sumatera-Indonesian traditional beverage, for bioethanol production. Microbiology Biotechnology Letter. 43 (3), 241 248.

Hommel, K., \& Ahnert, P. (1999). Introduction yarrowia (Candida) Lipolytica. Academic Press.

Maris, A., Wisselink, W. H., Cipollina, C., Oud, B., Crimi, B., Heiinen, J. J., Pronk, T. J. (2010). Metabolome, transcriptome and metabolic flux analysis of arabinose fermentation by engineered Saccharomyces cerevisiae. Metabolic Engineering. 12 (1): 537-551.

Monir, U. M., Aziz, A. A., Yousuf, A., Alam, Z. M. (2019). Hydrogen-rich syngas fermentation for bioethanol production using Saccharomyces cerevisiea. International Journal of Hydrogen Energy. 44(39): 1-9.

Nidetzky, B., Novy, V., Krahulec, S., Longus, K., Klimacek, M. (2013). Co-fermentation ofhexose and pentose sugars in aspent sulfite liquor matrix with genetically modified Saccharomyces cerevisiae. Biosource Technology. 130(1): 439448.

Olofsson, K., Bertisson, M., \& Liden, G. (2008). Short review on SSF - an interesting process option for ethanol production from lignocellulosic feedstocks. Biotechnology for Biofuels. 1 (7): 1 14

Ruruani, E., Sunarti, T.C., Meryandini, A. (2012). Yeast Isolation for bioethanol production. Hayati Journal of Bioscience. 19(3): 145-149.

Sibirni, A. A., Fedorovych, V. D., Sybirna, O. N., Yatsyshyn, Y. V., Dmytruk, V. K. (2011). Metabolic engineering and classic selection of the yeast Candida famata (Candida flareri) for Construction ofstrains with enhanced riboflavin production. Metabolic Engineering. 13(1): 8288.

Sun, F. \& Q. Sun. (2015). Current trends in lignocellulosic analysis with chromatography.Annals of Chromatography Separation and Technique, 1(2), 1008.

Tang, Q., Zhu, F., Cao, X., Zheng, X., Yu, T.,Lu, L. (2019). Cryptococcus laurentii controls gray mold of cherry tomato fruit via modulation of Ethylene-associated immune responses. Food Chemistry. 278 (2019): 240-247.

Voon, Y. Y., Hamid, A. S., Rusul, G., Osman, A., Queck, Y. S. (2006). Physicochemical, microbial and sensory changes of minimally processed durian (Durio zibethinus cv. D24) during storage at 4 and $28 \circ \mathrm{C}$. Postharvest Biology and Technology. 42: 168-175.

Yang, M., Kuittinen, S., Zhang, J., Vepsalainen, J., Keinanen, M., Pappinen, A. (2015). Co- 
Fermentation of hemicellulose and starch from barley straw and grain for efficient pentoses utilization in acetone-butanol-ethanol production. Biosource Technology.179 (1): 128-135.
Zhu, Y.Z., Yu, N., Liu, Y., Zhang, YJ., Zhang, MY. (2017). Chromatographic analysis and preparation of L-arabinose from corncob by acid hydrolysis. Industrial Corps and Products. 95 (1): 163-169. 